
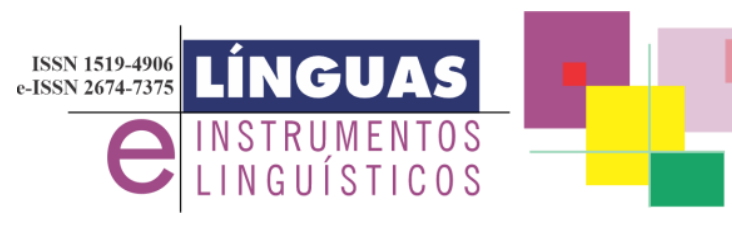

DOI: $10.20396 /$ lil.v24i48.8666232

\title{
Quando as línguas não fazem fronteira
}

\author{
When languages do not border
}

\section{María Teresa Celada*}

USP

Resumo: A partir de inquietações produzidas pela existência do que considero que é uma fronteira entre Brasil e América Latina, focalizarei como são significados os vários aspectos do funcionamento da fronteira nos dizeres de sujeitos que habitam e transitam a divisa geográfica e política traçada entre Brasil e os países de Uruguai, Argentina, Paraguai e Bolívia. Um aspecto crucial, embora não exclusivo, consistirá em observar a constituição de subjetividades específicas e qual tipo de relação essas travam com as línguas.

Palavras-chave: Fronteira, Subjetividades, Língua(s).

Abstract: Based on the concerns produced by the existence of what I consider to be a border between Brazil and Latin America, I will focus on how the various aspects of the functioning of the border are signified in the words of individuals who inhabit and transit the geographical and political boundary drawn between Brazil and the countries from Uruguay, Argentina, Paraguay and Bolivia. A crucial aspect, although not exclusive, will consist in observing the constitution of specific subjectivities and what kind of relationship these have with languages.

Keywords: Border, Subjectivities, Language(s). 


\section{Distintas fronteiras}

A partir de meu lugar de pesquisa que, em boa parte, está fortemente vinculado às políticas de língua que atravessam o Cone Sul e, especificamente, à relação do português e do espanhol nesse espaço, considero necessário dar destaque a uma fronteira que não (necessariamente) corresponde à divisa traçada no território e no mapa. No caso, refiro-me a que funciona entre o Brasil e a América Latina. Como uma forma de evocar pontos de sua constituição bem como alguns dos efeitos que produz seu funcionamento, farei uma breve menção a três trabalhos, desenvolvidos em diferentes áreas de estudo.

Começarei pelo livro de Rodrigues (2012), no qual, a partir da Análise do Discurso materialista, é estudado o lugar dado ao espanhol dentro do arquivo jurídico e legislativo da educação no Brasil. Na análise dos projetos de lei que propuseram a introdução do espanhol no curriculum da escola, a autora dá destaque ao mito celta da "Ilha-Brasil" e às especiais significações que foi tomando no contexto de colonização e de formação do Brasil como nação (RODRIGUES, p. 256-273). Ressalto alguns dos sentidos que, segundo a pesquisa de Rodrigues, comandaram boa parte desse processo: predestinação, exclusividade, isolamento - significantes que contribuem, nesta sucinta apresentação, com sua singular força expressiva.

No campo da história, no artigo intitulado "O Brasil e a distante América do Sul", Prado (2001) discute a produção de um discurso político, no século XIX, que - do seu ponto de vista - "fundou uma certa interpretação brasileira sobre o mundo hispano-americano, contribuindo para a constituição de um imaginário sobre a outra América, que a dissocia e separa do Brasil". Meus grifos marcam os sentidos sobre os quais a autora (ibid., p.128) se debruça, já no parágrafo introdutório desse texto, ao se referir a esse país como sendo e, ao mesmo tempo, não sendo América Latina ${ }^{1}$. É justamente essa "existência contraditória" a que a leva a propor uma reflexão - que aqui não acompanharemos - ao redor do "fosso que nos separa" (ibid.: 128) (destaques meus).

Por fim, no plano da reflexão literária, Schwartz (1993, p.126) inicia o artigo "iAbajo Tordesillas!" com uma pergunta que retoma a metáfora da "ilha": 
¿Podríamos considerar todavía válidas las palabras de Mário de Andrade, cuando en abril de 1926 afirmaba que 'no rincão da Sulamérica o Brasil é um estrangeiro enorme'? (destaques meus).

A pergunta desata, na reflexão que o autor desenvolve no texto, uma série de reflexões ao redor da relação assimétrica que haveria entre a prática de leitura da literatura brasileira que fizeram críticos e autores hispano-americanos e a que realizaram os brasileiros da literatura hispano-americana. No caso, a assimetria se vincularia a uma formulação clássica que se coloca em termos simplificadores: seria mais fácil para o brasileiro ler em língua espanhola do que o leitor hispano-falante ler em português.

Nesses três estudos, algumas formas de dizer referem ao funcionamento da fronteira que afirmo existir entre o Brasil e a América Latina / entre a América Latina e o Brasil. "Fosso" e "ilha" são dois significantes que condensam boa parte desse funcionamento e que ressoam numa série de pré-construídos que atravessam regularmente certos discursos nesse país. Mencionarei três deles: "o Brasil dá as costas para a América Latina", "o Brasil é uma ilha na América Latina”, "somos o único país que fala português".

Neste texto, no entanto, aproveitando as inquietações produzidas por essa discursividade, me debruçarei sobre aspectos do funcionamento da fronteira delimitada no mapa e no território. Algo me diz que esse movimento é valido; sigo, portanto, essa intuição, que essa fronteira (ou parte dela) tem algo ou muito a dizer.

Confesso, que ela sempre me atraiu especialmente e, em muitos casos isto se deveu ao fato de ter acompanhado os instigantes trabalhos que aqui darão impulso a minha reflexão. Refiro-me, especialmente, ao de Ana Maria Camblong (UNaM), desenvolvido numa linha da Semiótica marcada por seu modo singular de (re)(des)territorializar essa disciplina; ao de Eliana Sturza (UFSM), na linha da Semântica da Enunciação; ao de Verli Petri (UFSM) e ao de Marilene Lemos (UFSS) - ambos dentro da Análise do Discurso de linha materialista. Cabe destacar que, em todos os casos e com as respectivas especificidades, se trata de trabalhadoras da fronteira. 
Neste texto, observarei, portanto, aspectos do funcionamento da fronteira do Brasil com países da América Latina, no caso, com alguns dos sete que têm a língua espanhola como oficial. Essa divisa apresenta especificidades em seu trânsito e, portanto, em suas diversas formas de funcionar. Algumas delas se farão presentes neste texto, no qual recolho, em primeiro lugar, fragmentos de depoimentos extraídos de um documentário brasileiro, nos quais os sujeitos, habitantes de uma parte dessa vasta extensão fronteiriça, falam de suas vivências. Em segundo lugar, considerarei a definição de fronteira tal como formulada em dois dicionários, produzidos - como apresentarei em detalhe - por alunos de escolas da cidade de Itaqui, na fronteira de Rio Grande do Sul com Argentina.

Confesso que, do mesmo modo que a questão da fronteira territorial, a delimitação desse arquivo foi se impondo para mim pelo próprio gesto ao qual ambos os tipos de produções parecem responder, dentro de uma linha de sentidos que vai na contramão desse modo de dizer tão regular, segundo o qual "o Brasil dá de costas para a América Latina". Passo, então, a explorar esse arquivo.

\section{A voz, com habitantes da fronteira}

Da mão do leitor, passarei a ler e interpretar um conjunto de fragmentos de fala tomados do documentário "Portuñol", da jovem diretora gaúcha Thais Fernandes (2020). O título, em espanhol, parece funcionar, via metonímica, como metáfora da fronteira. Além disso, interpreto que antecipa uma posição discursiva central na produção da composição: ao se debruçar sobre a fronteira, a transita e a atravessa, para mostrar os dois lados, trabalhando as relações entre o Brasil e parte da América Latina e, em vários momentos, marcando como ele é visto a partir do outro.

Sob o formato de uma viagem, a edição do documentário acompanha os vaivéns do trânsito, assumindo uma certa estética da dispersão que parece ir ao encontro de um traço constitutivo do funcionamento da fronteira: no caso, especificamente, de diversos pontos da divisa brasileira com Uruguai, Argentina, Paraguai e Bolívia. Desse modo, visita e revisita cidades e espaços, em cada caso, reitero, de ambos lados da divisa. A partir dessa suscinta contextualização, passo a distribuir os fragmentos em séries numeradas para facilitar 
posteriores referências e, no encabeçamento de cada uma, registro alguns aspectos das condições mais específicas de sua produção. Convém registrar ainda que eles seguem a ordem na qual aparecem no documentário, fazendo parte, em muitos casos, de depoimentos mais amplos:

S1. Vozes anônimas citadas na introdução do documentário:

Fronteira é algo que no real não existe.

Fronteira, essencialmente, é um problema.

S2. Do depoimento de morador de Puerto Quijarro (Bolívia), que atravessa a fronteira cotidianamente para vender na feira livre de Corumbá (Brasil):

Aprendemos la lengua fácil.

[Brasil] Es un país más grande y nos tratan de manera marginalizada.

El único problema es la federal (fazendo referência à polícia).

Especialmente nosotros guardamos en casas de brasileños nuestras cosas, ¿no? Como nosotros no podemos atravesar de este lado, ahí pagamos una franquía por mes y nos dejan guardar nuestras cositas y entrar y salir de sus casas todos los días.

S3. Do depoimento de morador na fronteira entre Pedro Juan Caballero (Bolívia) e Ponta Porá (Brasil), dividida pela linha imaginária que atravessa o meio de uma avenida:

No tendría que ser frontera, tendría que ser fusión.

S4. Do depoimento de Javier Rodas, diretor da "Escuela Intercultural Jasy Porã”, Puerto Iguazú (Argentina):

Veintiún años caminando con los hermanos, haciendo trabajo de alfabetización e investigación.

Las fronteras son fenómenos producidos por la política.

Tendríamos que erradicar las fronteras, acercarnos y ser todos seres humanos y hermanos.

S5. Do depoimento de Rosario Brochado, professora e pesquisadora, do lado uruguaio:

Las fronteras no son líneas que separan sino que son zonas que tienen su vida propia y que deben ser respetadas.

El otro es diferente a ti porque habla otro idioma y tiene otras costumbres pero no hay conflicto en la convivencia. Me parece que la 
frontera es la encargada de dar el gran discurso de la diversidad que es el que necesitamos para nuestros tiempos.

S6. Do depoimento pronunciado em Sant'Ana do Livramento (Brasil), no limite com Ribera (Uruguai):

A linha é imaginária e as pessoas não querem ver a linha.

S7. Do depoimento de músico que mora do lado uruguaio da fronteira com Brasil:

Para mí la frontera es una identidad, o sea, fuera el candombe lo que me identifica más a mí es la frontera, también la influencia brasileña mucho en mí (sic), en mi personalidad [...]

Aprendí a hablar portugués, español y portuñol juntos, o sea, para mí son mis tres idiomas natales.

S8. Do depoimento de Suzana Mancilla, professora e pesquisadora, Puerto Quijarro (Bolívia), na fronteira com Brasil:

[na fronteira, fazendo referência à tramitação com a polícia]: Você é chamado a se identificar: quem é você? Por exemplo, eu com meu fenótipo boliviano, com identidade brasileira, as pessoas nunca olham minha identidade, vão olhar minha cara, vão dizer você é boliviana. Toda vez tinha revista para ver se estávamos levando alguma coisa. [de barca, pelo rio] Al mismo tiempo que tú ves una línea divisoria, es decir que te dicen que hay una línea divisoria y tú no la ves, tú dices: allí, en algún lugar hay una frontera, hay una línea que nos divide, pero, en realidad, lo que tú ves es la práctica del tránsito.

Por un lado, tú dices es la división, pero, por otro, es la aproximación.

S9. Vozes anônimas citadas no encerramento do documentário:

Hallo que significa frontera aquello que es una entrada para otro país.

Existe a fronteira em construção, hoje, amanhã e depois.

Ela demarca, separa e junta.

Os dizeres, enunciados a partir das diversas geografias que fazem parte desse espaço ${ }^{2}$, falam por si. Todos trazem as numerosas práticas que, de modos diversos, compõem o trabalho de habitar esse "espaço de fronteira" (LEMOS, 2020) passando da divisa seca, onde uma linha imaginária divide uma avenida ${ }^{3}$ ao limite traçado por um rio. Nesse conjunto de séries, as línguas alternam e chegam a dar sustento a enunciações propositivas que, a partir da reflexão sobre a fronteira e sua complexidade, projetam ressemantizações e - em muitos casos, 
mediante negações - insistem em marcar a necessidade de descristalizar determinadas formas de significá-la: "No tendría que ser frontera, tendría que ser fusión." (S3); "Por un lado, tú dices es la división, pero, por otro, es la aproximación" (S8).

Para abordar esse conjunto de recortes, considero que um gesto produtivo será começar por colocá-los em relação com a reflexão que Camblong (2009) vem produzindo. Suas formulações são realizadas a partir da província argentina de Misiones, topónimo no qual se faz presente a empresa jesuítica (ibid., p.125). Geograficamente, a própria autora (ibid.) descreve esse espaço como um apêndice territorial traçado por dois grandes rios internacionais: o Paraná e o Uruguai, e abraçado em uns $80 \%$ de seu perímetro, por Paraguai e Brasil. Vale a pena se situar no mapa:

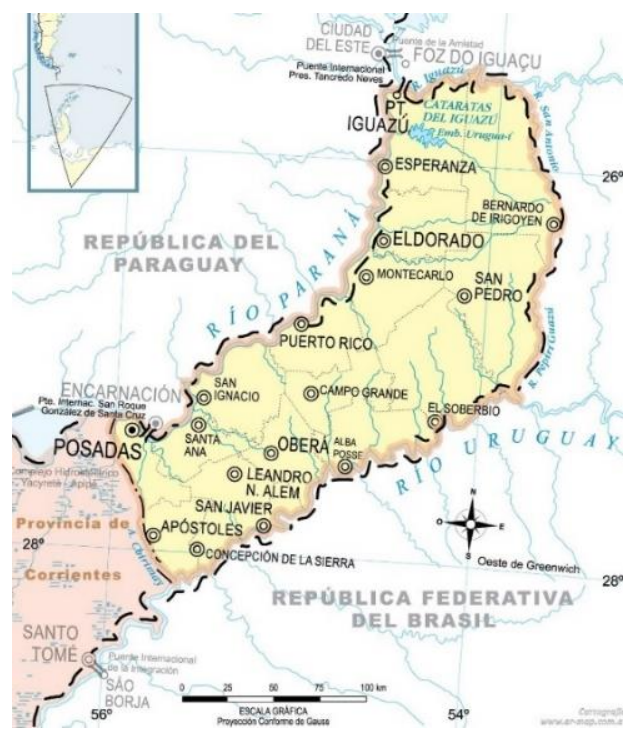

Imagem 1 - A província de Misiones (Argentina) no mapa.

Fonte: http://mapoteca.educ.ar/.files/index.html.1.15.html

Uma das formulações da pesquisadora que permite recuperar boa parte dos sentidos presentes nas séries recolhidas do documentário se materializa na seguinte afirmação: 
la estancia perpetua en la frontera agudiza el relieve del límite trazado por la historia y pone en carne viva la experiencia de lo contingente. (CAMBLONG, 2009, p.126)

A apertada síntese atingida pela autora encontraria possíveis paráfrases e expansões na interpretação que passo a tecer. $\mathrm{O}$ fato de habitar a fronteira intensifica o "relevo" do traçado de uma delimitação que, cotidianamente, como determinação histórica, precipita as possibilidades da contingência à qual a experiência se submete; operaria, nesse sentido, uma radicalização da contingência. Da perspectiva da Análise do Discurso, é possível reconhecer que, nesse espaço, há um confronto permanente entre atualidade e memória e se expressa em vicissitudes e avatares próprios - cf. na série 5: "[las fronteras] son zonas que tienen su vida propia" - bem como em formas específicas do aleatório. Assim, como será detalhado no próximo parágrafo, seus habitantes são submetidos a uma forte injunção, que vai se resolvendo em formas de aceitar, de dar um jeito, de driblar e/ou transgredir, enfim, de se virar para, nessa dura lex (CAMBLONG, ibid.), sobreviver. Parece se tratar, portanto, de uma experiência capaz de lacear as malhas das subjetividades envolvidas.

A autora (ibid., p.127) se refere a boa parte dessa contingência ao dizer que o habitante da fronteira sabe, pela própria experiência, que, ao cruzar o rio, a linha ou a alfandega, está em outra língua, em outro país, com outra moeda, em outra lei; por isso, conclui que esse trânsito não implica estranhamento, já que do outro lado estão os mesmos vizinhos que "naturalmente" falam guarani ou espanhol ou português. E ainda acrescenta: "Sabemos cambiar dinero como sabemos cambiar o mezclar las lenguas, sabemos estar aquí como sabemos estar allá" (ibid., p.127). Em muitos casos, acrescento, dependendo do ponto da divisa, também sabem que cotidianamente deverão entrar na fila de transeuntes para passar pelo crivo da alfandega que, insistentemente, registra seus ires e vires pela fronteira. Note-se que nesse movimento diário, intenso e, no caso, fortemente vinculado ao fato de ter que atravessá-la, os sujeitos são chamados a se identificar: "quem é você?" - tal como aponta a brasileira com fenótipo de boliviana na S8. De acordo com Pêcheux (1992, p.30), eles se submetem a certas marcações ou classificações: as relacionadas com as técnicas de gestão social dos 
indivíduos, segundo as quais são identificados, comparados, classificados, reunidos e separados de acordo, em nosso caso, com o fato de "ser de cá" ou "ser de lá".

Nesse sentido, justamente, a própria Camblong (ibid.) conclui:

Si el dilema clásico interroga y oscila entre "ser o no ser", nuestras especulaciones se deslizan y se detienen en la disyunción "estar o no estar", ésa es la cuestión en la dura lex de la supervivencia. (CAMBLONG, 2009, p.126)

De acordo com essa formulação, o ser (uruguaio, argentino, paraguaio, brasileiro, boliviano) fica submetido ao estar. Por efeito das referidas técnicas de gestão social (PÊCHEUX, ibid.), próprias do funcionamento do espaço administrativo (jurídico, económico, político) presente, como disse, em certos pontos de uma fronteira opera uma coerção lógica disjuntiva que qualifica o ser como "nacional" ou como "estrangeiro". Assim, esse "ser", no caso da estância movimentada, da agitação cotidiana do habitante da fronteira, se subordina permanentemente ao espaço no qual se encontra. Fica sujeito às inflexões relativas ao "onde" está: "estar na Argentina ou estar no Paraguai com o vizinho que fala guarani yopará"; "estar no Paraguai ou estar no Brasil, com quem compra na minha barraca e fala brasileiro" fatos esses que recaem diretamente sobre as subjetividades dos indivíduos, atravessadas pelos mandatos unilaterais do Estado nacional que os interpelou/interpela como cidadãos. Por isso, a própria autora acrescenta que "la continuidad de estar y no-estar tiende a estallar en pluralidades" (CAMBLONG, 2009, p.126): boa parte das quais, deduzo eu, respondem às diferenças às quais os sujeitos são submetidos pelo específico tratamento que o simbólico faz do real (LACAN, 2008) de um e outro lado da fronteira internacional.

Neste ponto, será produtivo observar que, no conjunto de séries tomadas do documentário - plenas de modos de significar a fronteira se faz presente a constelação de termos que Orlandi (1996) mobiliza para falar de entremeio. ${ }^{4}$ Retomo aqui, numa ordem que permitirá estabelecer certas concatenações, os diversos termos que a integram. Considero, de fato, que todos eles condensam os sentidos que se fazem presentes no funcionamento da "fronteira": 


\section{continuidade-descontinuidade \\ contradição \\ dispersão \\ desterritorialização}

Para abordar o primeiro, que encontraria uma possível síntese na forma "(des)continuidade", cabe trazer a série metonímica que, na Introdução à Arqueologia do saber, Foucault (2008) desenvolve para falar do trabalho do historiador: limite, ruptura, corte, mutação, transformação, umbral. Nas séries de enunciados tomados do documentário "Portuñol", reconhecemos o investimento colocado no lidar diário com a fronteira como limite e, ao mesmo tempo, também como umbral, isto é, como local ou passagem de entrada - sentido também central na reflexão de Camblong (ibid.). Alguns enunciados tomados do documentário materializam esses sentidos: "[Brasil] Es un país más grande y nos tratan de manera marginalizada. El único problema es la federal" (S2) e "Hallo que significa frontera aquello que es una entrada para otro país" (S9).

Considero que essa relação de (des)continuidade que quero destacar encontra expressão na epígrafe que encabeça a Introdução com a qual Bhabha abre seu livro, $O$ local da cultura, e que corresponde a uma formulação de Heidegger: "Uma fronteira não é o ponto onde algo termina, mas como os gregos reconheceram, a fronteira é o ponto a partir do qual algo começa a se fazer presente" (BHABHA, 2003, destaques meus). ${ }^{5}$ A definição já contribui a trazer as formas como $\mathrm{O}$ traçado da divisa instala a contradição, que é de ordem histórico e não lógico (PÊCHEUX, 1980). Para Camblong (ibid., p.128), a "dinâmica" da fronteira - seu funcionamento - não supera ou neutraliza tal contradição, na verdade, a sustenta, a reproduz, a potencializa e a transforma em continuidade. Aspectos ou figurações dessa índole contraditória encontram expressão em fragmentos da S3: "No tendría que ser frontera, tendría que ser fusión" ou da 8: "por un lado, tú dices es la división, pero, por otro, es la aproximación"; "hay una línea que nos divide, pero, en realidad, lo que tú ves es la práctica del tránsito". No entanto, penso que o ponto mais alto dessa expressão se faz especialmente presente num outro enunciado dessa última série: "eu com meu fenótipo boliviano, com identidade brasileira, as pessoas 
nunca olham minha identidade, vão olhar minha cara, vão dizer você é boliviana".

Colocar a fronteira em relação com o termo "dispersão", o terceiro dos mobilizados por Orlandi (1996) para falar em entremeio, me leva irremediavelmente a pensar na ameaça contínua que, da perspectiva do Estado nacional, ela representa para as várias formas de unidade imaginária produzidas "eficazmente" por ele: uma nação - um território / uma língua / um povo / uma bandeira. No entanto, o que me parece relevante destacar é a outra face desse processo de interpelação que submete os sujeitos que habitam a fronteira a uma permanente (des)(re)territorialização (o último termo da constelação formulada por Orlandi), tão presente nos enunciados que abordamos. Retomo, nesse sentido, um dizer presente na S5: "El otro es diferente a ti porque habla otro idioma y tiene otras costumbres pero no hay conflicto en la convivencia" (grifos meus). A estrutura negativa em destaque parece remeter, por efeito de memória (COURTINE, 2009), a uma formulação afirmativa, à qual se contrapõe e que corresponde ao interdiscurso, no caso, ao discurso do Estado. Por sua parte, o dizer formulado pelo enunciado citado permite observar que a dispersão não se coloca como ameaça, mas como algo ao qual o sujeito se expõe, aceitando os devires que ela exige, com as orientações ou direções rizomáticas que possibilita (Deleuze e Parnet, 1980, p.6). Agora, no decorrer deste texto, opto por me concentrar num ponto, ao considerar que uma das formas mais ricas nas quais essa (des)(re)territorialização ocorre se dá com relação à(s) língua(s).

A afirmação "Aprendemos la lengua fácil" (S2) encontra eco em outros enunciados extraídos do documentário: "você aprende sem querer", "aprendí a hablar portugués, español y portuñol juntos, o sea, para mí son mis tres idiomas natales" (S7). Este ponto de reflexão abre passagem para a segunda parte do corpus, pois outra significativa materialização desse modo de se relacionar com a(s) língua(s) se faz especialmente presente no verbete definidor de "fronteira", formulado por alunos de uma escola do município de Itaqui (RS) numa obra que leva o título de Dicionário Compartilhado de Língua de Fronteira, edição Otávio Silveira, de 2014. Antes de citá-lo, terei que apresentar alguns aspectos das suas condições de produção, que envolvem um expressivo gesto de extensão/intensão universitária. ${ }^{6}$ 
Na introdução a essa obra ("Sobre o dicionário"), a partir da pergunta acerca do que significa fazer um dicionário como esse, Petri observa que "Significa reunir crianças e jovens que estudam em escolas da região da fronteira do Brasil com a Argentina" para pensar sobre a língua que eles falam e os constitui (PETRI, 2014, s/n). Com relação ao modo como o trabalho se desenvolveu, a pesquisadora esclarece que foi o fruto de uma parceria entre o Programa de Educação Tutorial (PET) do Curso de Letras da Universidade Federal de Santa Maria (UFSM) e o Programa das Escolas Interculturais de Fronteira (PEIF), criado em 2005 como uma iniciativa do Ministério de Educação do Brasil. Em 2014, sob a coordenação da Profa. Eliana Sturza dessa mesma universidade, foi iniciada a realização de duas obras na região fronteiriça entre Brasil e Argentina, na cidade brasileira de Itaqui-RS no caso, em duas escolas: a Otávio Silveira e a Vicente Solés.

Vemos que esses dicionários são fruto de uma construção vinculada à tomada de posição de uma equipe que decide dar a voz a alunos de ambas as instituições para fazer um dicionário. O gesto, sem dúvida, implica uma intervenção no próprio espaço, no caso, pensado a partir da dimensão enunciativa formulada por Guimarães (2002) no qual as obras são publicadas. Nesse sentido, afeta a relação dos alunos envolvidos com a língua que falam e, também, vem a legitimá-la na escrita de ambos os dicionários.

Como sublinha a própria Petri $(2014, \mathrm{~s} / \mathrm{n})$, a partir da língua que os constitui, os estudantes de sétimo ano de ensino fundamental dessas escolas de Itaqui, sob a orientação de "Petianas de Letras" supervisionadas pela pesquisadora e com a colaboração de professores de Língua Portuguesa e de Língua Espanhola das escolas envolvidas, assumem a palavra. Mediante esse gesto, exercem o direito a delimitar a série lexical que seria objeto dessa obra - sob o reconhecimento da incompletude constitutiva desses instrumentos linguísticos - e constroem os respectivos verbetes e enunciados definidores.

Para a análise pontual que realizarei, parece-me pertinente mostrar a localização do município no mapa, com o intuito de que seja possível ver que, neste caso, se trata de uma fronteira não seca, constituída pelo rio Uruguai. Petri (2018, p.75), ao se referir a esse trecho da divisa, fala das fronteiras moventes do Sul do Brasil com a Argentina, e acrescenta que se trata de uma região "banhada pelo Rio Uruguai que, em períodos 
de enchentes, avança cidade adentro (do lado brasileiro), movendo a fronteira e agitando os sentidos sobre a própria noção de fronteira".

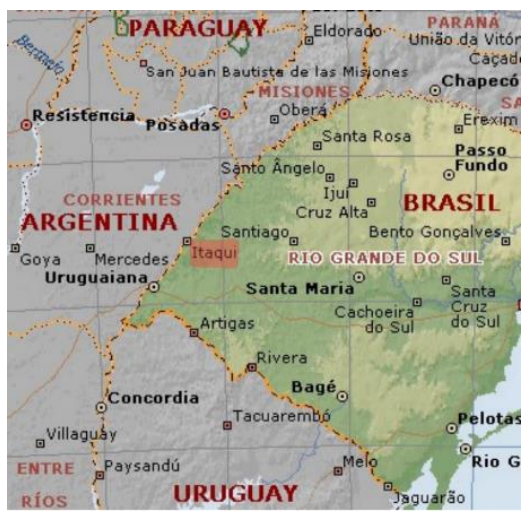

Imagem 2 - Fronteira Brasil -

Argentina. Destaque de Itaqui.

Fonte:

https://www.achetudoeregiao.com.br/rs/ $\underline{\text { RS.GIF/mapa_rio_grande_do_sul.gif }}$

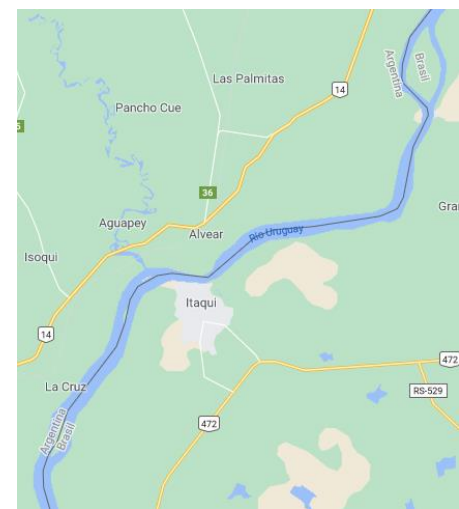

Imagem 3 - Itaqui à beira do rio Uruguai.

Fonte:

https://www.google.com/maps/@$29.1162991,-56.6487604,11 z$

Cabe, a seguir, como antecipado, trazer o primeiro verbete, nos atentando ao modo como nele se materializa a relação dos sujeitos desse espaço com as línguas:

Fronteira

Comunicação com outras línguas, com os Hermanos, correntinos, paisanos.

\section{Exemplo:}

Chalana é o barco de madeira que atravessa a fronteira.

Nessa formulação não deixa de surpreender a significativa afirmação de "fronteira" como "comunicação com outras línguas" (grifos meus), sobretudo se pensarmos que faz parte do único enunciado definidor do verbete, aspecto que, de alguma forma, o projeta como suficiente e capaz de dar conta dos sentidos do termo. A definição parece incluir algo que irrompe com a força do que se apresenta para o sujeito do discurso como naturalizado, como parte da "rotina" de habitar a fronteira: as línguas e a relação com elas. 
O sintagma "outras línguas" não é sujeito a especificação a não ser pela enumeração que se faz dos que parecem se apresentar como seus falantes. Os dois primeiros termos dessa enumeração são: "Hermanos" (grafado com maiúscula inicial) $)^{7}$ e "correntinos" - gentílico que, do lado argentino, faz referência àqueles que habitam precisamente a província de Corrientes (cf. Imagem 2) - e que funcionaria como uma especificação do primeiro termo, quase um genérico mobilizado pelo brasileiro em determinadas condições, para se referir aos povos hispano-falantes da América Latina ou do Cone Sul. O terceiro termo da enumeração, "paisanos", é uma palavra possível tanto em espanhol quanto em português. No caso, interpretando que ela poderia estar declinada nos sentidos específicos do espaço no qual o dicionário é produzido, recorremos à busca de seu significado no interior da obra, no qual a definição registra que "paisano" faz referência a "uma pessoa camarada".

Cabe destacar esse movimento especialmente significativo: as línguas não são especificadas, fazendo-se alusão a elas mediante a menção de falantes; nessa relação o que se apresenta como evidência remete às figuras desses "outros", sem os quais qualquer língua não existiria ou não teria razão de ser. Pela relação do texto com sua exterioridade, no entanto, é possível repor a referência da expressiva marca de plural presente no fragmento "comunicação com outras línguas": a diversidade linguística que inclui, como mínimo, o guarani (língua cooficial na província de Corrientes) e o espanhol bem como seus entremeios ${ }^{8}$, inclusive com o português do Brasil ${ }^{9}$. Nesse sentido, na materialidade da escrita do próprio verbete, a presença de formas em espanhol (uma dessas “outras línguas”) deixa marcas, do quanto essa língua é constitutiva do sujeito e de seus modos de dizer e de significar.

Encerrando o verbete que abordamos, o exemplo vai na direção dos sentidos presentes no enunciado definidor e marca, mais uma vez, o movimento do trânsito e/ou da transposição dessa fronteira: na definição, pela via da comunicação com outras línguas; no exemplo, pela referência à "chalana", mediante a qual se faz presente a densidade do corpo do rio.

A forma material da definição e do exemplo do verbete me leva a identificar uma posição discursiva - instigante na autoria de um dicionário - marcada pelo apego à concretude, à especificidade do saber construído na experiência imediata, não submetida a generalizações ou 
universalizações. A posição-sujeito está marcada pela identificação com os sentidos impostos pela fronteira internacional vivida em Itaqui, e com o universo ao qual ela dá passagem: o além da fronteira. A partir dessa identificação, pensando um pouco nos autores do dicionário, projeta-se uma certa idealização que, talvez, tenha a ver - diferente, no caso, à fronteira seca - com a distância que impõe o próprio rio que, na região, parece não contar com uma ponte.

No entanto, quando falo de "idealização" não pretendo dizer que os sentidos aparecem livres das relações contraditórias presentes nessa fronteira. Na procura, dentro do próprio dicionário, de formas vinculadas aos sentidos de "fronteira", me deparei com a definição de "atravessar cavalo" que aparece formulada como: "roubar cavalos da Argentina". No caso, o exemplo deixa claro a referência: "Meu pai foi preso por atravessar cavalo", no qual a fronteira aparece vinculada às relações de força que a habitam.

Passo agora ao verbete registrado no outro dicionário, produzido na escola Vicente Solés, bem mais extenso. Sua abordagem possibilitará que me concentre no que Pêcheux (1992) chama de "técnicas materiais" - que entram em relação com o tratamento que do real faz o simbólico. Dentre elas, ganhará destaque a significativa projeção de uma ponte imaginária.

Fronteira

1. É uma mistura de uma cidade com a outra, com as mesmas coisas, mas com diferentes línguas e coisas; país vizinho;

2. Divisa do Brasil com a Argentina;

3. Divisa de um certo lugar, estado ou país;

4. É uma divisa entre dois países; é um país;

5. Estado ou cidade que se limita com outros países, estados ou cidades;

6. Em Itaqui, temos o rio Uruguai, o porto, a balsa, a Igreja, o parcão e vários bairros.

\section{Exemplo:}

Passei da fronteira com Uruguai de carro e voltei de barco.

Vou para a fronteira.

A fronteira entre a Argentina e Itaqui são poucos metros de lonjura. Tivemos uma enchente na fronteira de Itaqui com Argentina em 2014. Ontem eu e meu amigo atravessamos a fronteira de barca. 


\section{Sinônimo:}

Divisão, barca, embarcação, rio, ponte, porto, limite

Na comparação com o verbete citado anteriormente, começo por destacar a importância de um movimento que trabalha outra posição autor e que vai do concreto e imediato - específico - na direção da generalização que é regular dentro da prática de produção de definições nos verbetes de dicionário. Esse movimento se materializa nas passagens da primeira acepção para a segunda e atinge seu clímax na de número 3. A quarta parece reiterar a anterior e, ao mesmo tempo, produzir um deslocamento significativo, por isso, a seguir, retomo as duas:

3. Divisa de um certo lugar, estado ou país;

4. É uma divisa entre dois países; é um país (destaques meus)

Após afirmar que se trata de uma divisa, a direção de sentidos instalada pela definição 4 parece desaguar nos sentidos disparados pelo fragmento grifado: "é um país". Um possível efeito de leitura é que "a fronteira é um país em si”, o que me leva a estabelecer uma relação com um enunciado presente na S5, retirada do documentário "Portuñol": "Las fronteras no son líneas que separan sino que son zonas que tienen su vida propia...", modo do dizer no qual, mais uma vez ganha presença uma negação a partir da qual opera uma forte ressignificação. Já a quinta acepção do verbete retoma, em boa parte, sentidos presentes nas anteriores e, por fim, a número 6 recupera a identificação com a concretude ao se falar daquilo que os habitantes de Itaqui têm nessa cidade: os objetos naturais (o rio) e os que são produto das "técnicas materiais" de que fala Pêcheux (1990, p.30). De acordo com o autor, elas visam produzir transformações físicas ou biofísicas constituindo "os meios de obter um resultado que tire partido da forma a mais eficaz possível dos processos naturais, para instrumentalizá-los, dirigi-los em direção aos efeitos procurados". Em nosso caso: o porto e a balsa, que materializariam a possibilidade de atravessar a fronteira. Ao mesmo tempo, a menção explícita do parcão, da igreja e dos vários bairros da cidade nos leva a interpretar que o corpo de Itaqui, em si, se interpreta aí como (espaço de) fronteira. 
Da sua parte, os exemplos registrados nesse verbete destacam, alguns aspectos: tal como aparecia no primeiro, sua transitabilidade (neste caso, de várias formas e em várias circunstâncias); e, também, o fato de poder ser o espaço em direção ao qual alguém se dirige e de ser, como antecipei, um "país" em si, com seus acontecimentos: o da enchente de 2014, por exemplo, na qual o protagonista é o rio. Na série de exemplos apresentados, se faz presente a outra fronteira próxima: a que o Brasil também faz com Uruguai (cf. imagem 2). E, ainda, chama a atenção o seguinte: "A fronteira entre a Argentina e Itaqui são poucos metros de lonjura" (grifos meus). O fragmento no qual aparece a medição, em destaque, sustenta uma relação específica entre "poucos metros" e o termo "lonjura" que, no Dicionário Houiass ${ }^{10}$, por exemplo, se vincula à ideia de "afastamento físico significativo", "grande distância", sendo seu antônimo "proximidade". No modo de dizer, marcado por uma contradição, parece se materializar um modo de significar a relação do sujeito com esse "outro lado" da fronteira.

Por fim, passarei à cadeia sinonímica que encerra o verbete: uma significativa marca de autoria. Nela, os significantes: “divisão, barca, embarcação, rio, ponte, porto, limite", podem ser distribuídos em duas séries; de um lado, divisão, rio, limite, que apontam à natureza intrincadamente vinculada aos efeitos de determinações que são da ordem da história; e, de outro, as já referidas técnicas materiais: barca, embarcação - onde o primeiro termo é reiterado mediante a presença do hiperônimo - e ponte, porto. Delineia-se aí o movimento de um sujeito que começa pelo registro do sentido de divisão, reiterado no desfecho de limite, e que entre esses dois termos insere termos que fazem referência aos meios que contribuem no tratamento que do real faz o simbólico: as técnicas materiais que instrumentalizam objetos e processos naturais. Na cadeia sinonímica que abordamos, os sentidos de divisão e limite emolduram uma série de significantes que giram ao redor do rio: elemento da natureza que se apresenta como passível de trânsito, mediante a série de elementos que permitem tal movimento o porto, a barca, a embarcação, a ponte.

É curioso observar que, como se deduz da apresentação que Petri (2018) faz dessa parte da fronteira sobre o rio Uruguai e da pesquisa que realizei sobre esse município, em Itaqui não há ponte. Esse aspecto pode funcionar, no imaginário dos autores, como falta, já que sua presença facilitaria a travessia da fronteira marcada pelo rio e 
materializada no corpo de suas águas. Nesse sentido, o registro do significante - que se dá na cadeia sinonímica, mas que não aparece nas definições nem nos exemplos - pode responder a um gesto de autoria, dentro do movimento para o qual me atentei ao abordar a série de definições que compõem o verbete. Esse gesto se sobreporia àquilo que é da ordem da concretude, do que "é observável” em Itaqui, e registraria o que se antecipa que não pode deixar de aparecer como sinônimo de fronteira.

A materialidade do verbete me leva a concentrar-me nesse gesto que, também, considero que é de interpretação: no processo de definir "fronteira" essa autoria faz questão de registrar o termo "ponte" o qual funciona, como diria Lemos (2020, p.148), na direção do deslimite. Na relação específica que aí se constrói e ainda de acordo com a reflexão dessa mesma autora (ibid., p.147), a ponte materializa o confronto e a contradição entre a constituição de um espaço imaginário de fronteira e a fluidez real do espaço. ${ }^{11}$ Por fim, acrescentaria que ele projeta o "ponto de referência" e o "monumento" (cf. LEMOS, ibid., p.141) com os quais Itaqui, como cidade, poderia contar. ${ }^{12}$

Com a força expressiva desse significante, ponto alto na reflexão sobre a fronteira que aqui me ocupa, encerro este item para passar a tecer as considerações finais.

\section{O horizonte do (im)possível}

A partir do corpus abordado e das reflexões por ele suscitadas, é possível dizer que, no espaço delimitado por essa fronteira e sempre dentro de desiguais e específicas relações de força, o simbólico, como tratamento do real (o impossível) (LACAN, 2008), se materializa de diversas formas. Algumas delas consistem na produção da série de técnicas materiais - como a ponte - aqui abordadas e na instauração de um espaço administrativo com suas múltiplas técnicas de gestão social, sendo a alfandega um caso paradigmático. Também, cabem entre essas formas os processos de interpelação dos respectivos Estados, que se concentraram historicamente em diversos discursos: os da escola são especialmente significativos. Com relação a essa enumeração, que não pretende ser conclusiva e que continuarei desenvolvendo, trata-se de aspectos todos atravessados pela prática da linguagem, no caso, habitada por diversas línguas e entremeios. 
Nesse funcionamento entre o real e o simbólico, também e de modo inevitável, entra o imaginário: no caso, no reconhecimento da diferença, mediante a pujante força da procura do laço entre as pessoas - a busca de vínculo humano/do vínculo entre indivíduos suposta no que Sturza (2010, p.341) chama de "relações fronteiriças" e que, segundo ela mesma, são de toda ordem: comerciais, interpessoais, profissionais, culturais, entre outras. Via esse imaginário - pelo qual, mesmo quando não é possível enxergá-la, se antecipa a linha divisória da fronteira opera uma mexida nos limites do possível e do impossível, pois $o$ possível vai empurrando o impossível.

Com relação à diversidade de práticas cotidianas que aparecem no arquivo abordado, muitas delas exploram a equivocidade que, ineludivelmente, atravessa a cobertura lógica de regiões heterogêneas do real, dentro de um mundo semanticamente normal (PÊCHEUX, 1992, p.32-34). Retomo, no caso, a que se referia ao contrabando na definição de "atravessar cavalo", registrada num dos dicionários, e, também, aquelas que apareciam na fala do morador de Puerto Quijarro, na Bolívia, ao apresentar o modo como organiza seu trabalho cotidianamente (S2). Lembremos que, com a finalidade de montar seu barraco na feira de Corumbá, todo dia cruza a fronteira e, para isso, por restrições colocadas pela Polícia Federal, conta com "os brasileiros": "Como nosotros no podemos atravesar de este lado, ahí pagamos una franquía por mes y nos dejan guardar nuestras cositas y entrar y salir de sus casas todos los días". A equivocidade - como possibilidade de que a interpretação possa trazer outros sentidos e não aqueles impostos pela projeção de um mundo "semanticamente normalizado" - abre espaço para que o sujeito dê sustento a práticas que empurram o impossível.

O funcionamento dos três registros (imaginário, real, simbólico) parece estar em forte relação com a constituição de específicas subjetividades. São elas as que - entendidas como malhas de saberessentidos-afetos (CELADA e PAYER, 2016, p.22) - suportam, na experiência cotidiana, uma forte injunção, fato esse que precipita singulares processos de identificação, tanto no registro do imaginário quanto do simbólico. A radicalização da contingência disparada pelo fato de habitar a fronteira - aspecto que abordei com base na reflexão de Camblong - demanda dos sujeitos uma lida perpétua e específica. O efeito parece consistir numa específica configuração que, para aproveitar um modo de dizer que já se fez presente nesta reflexão, 
chamaria de "subjetividade laceada". Nesse sentido, considerando que a identidade se refere, sempre, a "um feixe instável de traços que decantam de processos de identificação" (ZOPPI-FONTANA; CELADA, 2009), o que aqui ressaltamos é a presença de fatores que submetem os sujeitos a uma permanente (des)continuidade, marcada pela contradição que está em sua base.

Num trabalho escrito com Payer (CELADA; PAYER, 2016, p. 22) retomávamos a instigante formulação de Orlandi (2001, p. 99-100), segundo a qual a subjetividade diz respeito à qualificação do sujeito pela sua relação constitutiva com o simbólico. A partir do modo como o termo "qualificação" foi pensado nesse texto, considero que no espaço da fronteira abordado neste artigo as subjetividades são atravessadas por um singular cruzamento de atributos e qualidades que se referem à preparação e à disponibilidade de um sujeito para ser capaz de produzir a série de investimentos implícitos nas diversas práticas linguajeiras. A eles se faz referência quando se fala de "aprender uma língua com facilidade", quando alguém reconhece "ter três idiomas natais" ou quando esses sujeitos, simplesmente, vão no embalo dos entremeios das línguas. Esses fatos todos desafiam fortes mandatos relativos ao universo das línguas e da linguagem.

Em tais condições de produção estimula-se a configuração de identidades com certas marcas ou especificidades. Para compreender a afirmação no sentido em que a formulo faz-se necessário frisar o que Rodríguez-Alcalá (2011) ${ }^{13}$ conceitualiza ao incorporar uma importante complementação a definições centrais no campo da Análise do discurso. Afirma a autora (ibid., p. 246, destaques do original) que "sujeitos, sentidos e espaço se constituem num mesmo processo histórico", o que implica considerar que o espaço não é um "“cenário' neutro e exterior, mas constitutivo do processo do qual resultam sujeitos e sentidos". O espaço, acrescenta (ibid.), "constitui um aspecto fundamental das condições de produção", observação que a leva a concluir algo que se enlaça perfeitamente com o que aqui desenvolvo a respeito da configuração de específicas subjetividades: os processos de identificação subjetivos se dão num espaço produzido historicamente, nem concreto, nem abstrato, mas material.

Para concluir a reflexão me concentrando especialmente em sujeitos e língua(s) e pensando no modo como aspectos das condições de produção se articulam na definição que Guimarães (2002, p.18-19) 
realiza de "espaço de enunciação", diria que, de fato, o aqui delimitado está habitado por sujeitos divididos pelos direitos a dizer, aos modos de dizer e - acrescentaria - às línguas nas quais dizer. No conjunto das práticas discursivas vivas em ambos lados da fronteira, com base na definição desse mesmo autor (GUIMARÂES, sem data), diria que as "relações de línguas" passam por uma reconfiguração: as oficiais - ao redor das quais, nos respectivos Estados fronteiriços, as outras línguas se organizam - e as não oficiais, todas elas (re)(des)territorializadas e, com frequência, materializadas em entremeios.

Dentro do tratamento específico que aí opera do real (o impossível), as diferenças linguísticas, na contramão dos sentidos impostos pelo mito de Babel, não funcionam como condenações. Algo do saber dos sujeitos dessa fronteira os leva a não abrir mão das distintas línguas e das diferenças entre elas; os leva, enfim, a usufrui-las. A observação me permite pontuar, pelo menos, dois aspectos. Em primeiro lugar, nesse modo de relação, são propiciados singulares vínculos por parte de seus sujeitos com a linguagem, na contramão dos que operam no cerne do funcionamento de cada um dos respectivos Estados nacionais, de forte vocação monolíngue. No caso, a interpelação desses falha e os sujeitos não apenas exercem, mas também reivindicam seu direito a falar em várias línguas (incluindo o portunhol), com defesa de suas múltiplas e heterogêneas identidades linguísticas. Em segundo lugar, retomando o título deste artigo, é possível observar que, quando se encontram nesse modo de funcionamento, as línguas não fazem fronteira. E isso ocorre tanto na relação que mantêm entre si quanto no sentido de que não impedem a "comunicação" com o outro ou outros, que está/estão do outro lado da divisa. Lembro que o significante em destaque fazia referência a um "bem" central na definição de fronteira registrada no primeiro dos dicionários abordados.

Está claro que, no espaço analisado, certas interpelações são deslocadas porque outras se sobrepõem: nesse confronto, desmente-se a univocidade das prerrogativas dos Estados nacionais e, ao mesmo tempo, por uma espécie de funcionamento-entre, não se prescinde da existência deles. Como fruto dos modos de interpelação que aí surgem, temos o enunciado do uruguaio que na S7, tomada do documentário "Portuñol", afirma: "Para mí la frontera es una identidad, o sea, fuera el candombe lo que me identifica más a mí es la frontera", ao qual 
acrescenta: "también la influencia brasileña mucho en mí (sic), en mi personalidade".

Essa modalidade, na qual as subjetividades atingem qualificações específicas, me interpela fortemente, tanto como pesquisadora quanto como trabalhadora da educação. Ela, de fato, mostra um modo de funcionamento que, na pluralidade de seus aspectos, permite uma reflexão sobre as relações de/entre línguas, sobre a relação línguas/sujeitos, sobre os sujeitos.

Algo, como antecipei no primeiro item, se impôs quando comecei a escrever este texto, no qual faço considerações aspectos do funcionamento de um trecho da fronteira do Brasil com alguns países do Cone-Sul. É verdade que quando tomei a decisão de abordar o arquivo aqui apresentado tinha uma intuição; no entanto, não antecipava que olhar para esse espaço traria tantos elementos chave para compreender como pode acontecer o funcionamento-entre, mostrando, dentre outros aspectos, a possibilidade de que a Ilha-Brasil, se expondo às diferenças, perca suas claras delimitações fronteiriças e que as distintas línguas não façam fronteira. De fato, essa fronteira tem algo a nos dizer, tem algo a nos mostrar: todo um leque de sentidos ausente no funcionamento da discursividade que insiste em delimitar e manter a outra fronteira: a que afirmo que se faz presente, para além do território, entre o Brasil e a América Latina. Essa, sem dúvida, terá que ser objeto de um outro texto.

\section{Referências}

BHABHA, H. K. O local da cultura. Trad.: Myriam Ávila, Eliana L. de Lima Reis e Gláucia R. Gonçalves. Belo Horizonte: Editora UFMG, ( $2^{\mathrm{a}}$ reimpr.). 2003.

CAMBLONG, A. M. "Habitar la frontera” In: deSignis, n. 13, enerojunio, p.125-133, 2009.

CELADA, M. T. O espanhol para o brasileiro. Uma língua singularmente estrangeira. Tese. Doutorado em Linguística. Campinas: Universidade Estadual de Campinas, 2002.

CELADA, M. T. Fronteras discursivas. Desencuentro de sentidos y alteridad. In: Páginas de guarda, 6, primaveira, p. 40-56, 2008.

CELADA, M. T.; PAYER, M. O. "Sobre sujeitos, língua(s), ensino. Notas para uma agenda". In: Subjetivação e processos de 
identificação. Sujeitos e línguas em práticas discursivas - inflexões no ensino. Campinas: Pontes, p.17- 41, 2016.

CELADA, M. T.; PAYER . "Entremeio I", "Entremeio II", "Entremeio III". In: Vídeoverbete en ENCIDIS (Enciclopédia Virtual de Análise do Discurso). Niterói: Laboratório de Arquivos do Sujeito - UFF, 2017. COURTINE, J-J. ([1980] 2009) Análise do discurso político. O discurso comunista endereçado aos cristãos. Trad.: Carlos Piovezani, Vanice Sargentini et alii. São Carlos: EdUFSCar.

DELEUZE, G.; PARNET, C. Diálogos. Trad.: José Vázquez. Valencia: Pre-textos, 1980.

FOUCAULT, M. A arqueologia do saber. Trad.: Luiz F. Baeta Neves. Rio de Janeiro: Editora Forense Universitária, $7^{\mathrm{a}}$ ed., ( $3^{\mathrm{a}}$ reimpr.)., 2008. GUIMARÃES, E. Semântica do Acontecimento. Campinas: Pontes, 2002.

GUIMARÃES, E. (s/d). Relações de línguas. Enciclopédia das línguas do Brasil. Disponível em:

<https://www.labeurb.unicamp.br/elb2/pages/artigos/lerArtigo.lab?id= 1>. Acesso em: 23 de junho de 2021.

LACAN, J. ([1973] 2008). O seminário, libro 11: Os quatro conceitos fundamentais da psicanálise. Trad.: M.D. Magno. Rio de Janeiro: Jorge Zahar.

ORLANDI, E. "Entremeio e discurso." In: Interpretação. Autoria, leitura e efeitos do trabalho simbólico. Rio de Janeiro: Vozes, p.2335, 1996.

ORLANDI, E. Do sujeito na História e no Simbólico. In: ORLANDI, E. Discurso e texto. Formulação e circulação dos sentidos. Campinas: Pontes, p. 99-108, 2001.

PÊCHEUX, M. Remontémonos de Foucault a Spinoza. Trad. por Miguel Rodríguez. In: MONTEFORTE TOLEDO, M. El discurso político. México: UNAM/Nueva imagen, p.181-199, 1980.

PÊCHEUX, M. "Delimitações, Inversões, Deslocamentos." In: Cadernos de Estudos Linguísticos, n.19. Campinas: Unicamp. p. 724, 1990.

PÊCHEUX, M. O discurso. Estrutura ou acontecimento. Trad.: Eni P. Orlandi. Campinas: Pontes, 1992.

PETRI, V. "Fronteiras moventes, sentidos deslizantes.” In: ORLANDI, E.P., MASSMAN, D. e DOMINGUES, A.S. Linguagens, instituições e práticas sociais. Pouso Alegre: Univas, p.172-188, 2018. 
PRADO, M.L. O Brasil e a distante América do sul. Revista de História 145, 127-149, 2001.

RODRIGUES, F.C. Língua viva, letra morta. Obrigatoriedade e ensino de espanhol no arquivo jurídico e legislativo brasileiro. São Paulo: Humanitas/FAPESP, 2012.

RODRÍGUEZ-ALCALÁ, C. Discurso e cidade: a linguagem e a construção da "evidência do mundo". In: RODRIGUES, E.A., SANTOS, G.L. de (Orgs.). Análise do discurso no Brasil: Pensando o impensado sempre. Uma homenagem a Eni Orlandi. Campinas, RG Editora, p.243-258, 2011.

SCHWARTZ, J. Abaixo Tordesilhas! Estudos Avançados, São Paulo, n. 7 (17), 185-200, 1993.

STURZA, E. R. "No Tempo e no Espaço: Mapeando as Línguas de Fronteira" In: Congresso Internacional de Professores de Línguas Oficiais do MERCOSUL; I Encontro Internacional de Associações de Professores de Línguas Oficiais do MERCOSUL Línguas, sistemas escolares e integração regional. Foz do Iguaçu, p.1-7, 2010.

TATIÁN, D. "La invención y la herencia. Notas liminares para una universidad abierta." In: Caracol, n. 16, p.66-84, julho-dezembro, 2018.

ZOPPI-FONTANA, M.; CELADA, M.T. "Sujetos desplazados, lenguas en movimiento: identificación y resistencia en procesos de integración regional.” In: Signo \& Seña, núm. 20, p. 159-180, 2009.

\section{Dicionários}

Dicionário compartilhado de Língua de Fronteira. Programa das Escolas Interculturais de Fronteira - PEI, coordenado pelo grupo PETLetras das UFSM. Itaqui: Edição Otávio Silveira, 2014.

Dicionário compartilhado de Língua de Fronteira. Programa das Escolas Interculturais de Fronteira - PEI, coordenado pelo grupo PETLetras das UFSM. Itaqui: Edição Vicente Solés, 2014.

\section{Documentário}

FERNANDES, T. "Portuñol”. Distribuição: Lança Filmes. Produção: Vulcana Cinema, coprodução: Epifania Filmes, Globo Filmes e GloboNews. 70 minutos, 2020. 


\section{Notas}

* Doutora em Linguística pela Universidade Estadual de Campinas (Unicamp). Professora da Faculdade de Filosofia, Letras e Ciências Humanas da Universidade de São Paulo - FFLCH-USP.

${ }^{1}$ Para tanto, toma como base formulações de Edmungo O'Gorman em: A Invenção da América. México: FCE, 1958.

2 Como veremos na terceira parte deste texto, compreendo "espaço" no sentido no qual é conceitualizado por Rodríguez-Alcalá (2011). Lemos (2020), a cujo trabalho farei referência ainda neste parágrafo, aborda o que chama de "espaço de fronteira" a partir dessa base conceitual.

3 "Solo con un paso estamos en otro país", observa uma voz no próprio documentário.

${ }^{4} \mathrm{Na}$ reflexão da autora, o objetivo é definir a análise do discurso como uma disciplina de entremeio; posteriormente, em vários trabalhos essa noção é mobilizada para aproveitar sua capacidade significante (CELADA, 2002; CELADA e PAYER, 2016; CELADA, 2017).

5 Martin Heidegger, "Building, Dwelling, Thinking". Já nos servimos da instigante formulação de Heidegger num texto prévio, no qual abordamos o que denominamos "fronteira discursiva" (CELADA, 2008).

6 Tatián (2018), na reflexão que realiza sobre o funcionamento contemporâneo das universidades, revisa o conceito de autonomia que faz questão de definir não como "clausura solitária", mas como "heterogeneidade solidária", o que o leva a tomar o conceito de Boaventura de Sousa Santos: "extensão no sentido contrário". Esse, da perspectiva de Tatián, incorpora saberes concebidos em outra parte e ideias cunhadas fora para compor uma conversa o mais distante possível da heteronomia do capital e do mercado. Para designar essa atenção a saberes estranhos às rotinas acadêmicas, o autor cunha o conceito de "intensão universitária".

${ }^{7}$ Deixo registro da presença regular desse significante (que apareceu na fala do diretor de escola, situada na Argentina, na S4) do qual, inclusive, deduzo que surge "mano", uma forma nominal regular em certas interlocuções no Brasil.

${ }^{8}$ Considero relevante trazer o termo que, a partir de Orlandi (1996), mobilizei para compreender o funcionamento da "fronteira" com a finalidade de, metonimicamente, nomear as línguas de mistura ou os entre-línguas que, nesse espaço, se materializam. Parece-me que os termos vinculados ao conceito orlandiano que aqui foram especificados (descontinuidade - contradição - dispersão - [des][re]territorialização) dão conta de sua constituição.

${ }^{9} \mathrm{E}$ que, também, pode contemplar a presença das comunidades de migrantes europeus, que chegaram nessa região no final do século XIX e inícios do XX.

${ }^{10}$ Edição on-line, consulta em 22-04-2021.

11 A autora toma as formulações de RODRÍGUEZ-ALCALÁ, C. (2018) em: "Nota sobre a noção de cultura e sua relação com a de civilização: o ocidente como observatório das formas de vida social". In: Fragmentum, n. Especial, julho-dezembro. Santa Maria: Editora Programa de Pós-Graduação em Letras, UFSM. 
${ }^{12}$ Lemos toma conceitos formulados por FEDATTO, C.P. (2013) em: Um saber nas ruas: O discurso histórico sobre a cidade brasileira. Campinas: Editora da Unicamp. ${ }_{13}$ Nesse texto, a autora atinge uma expressiva síntese de formulações realizadas em trabalhos prévios. 